\title{
Manager relations, psychological need satisfaction and intention to leave in the agricultural sector
}

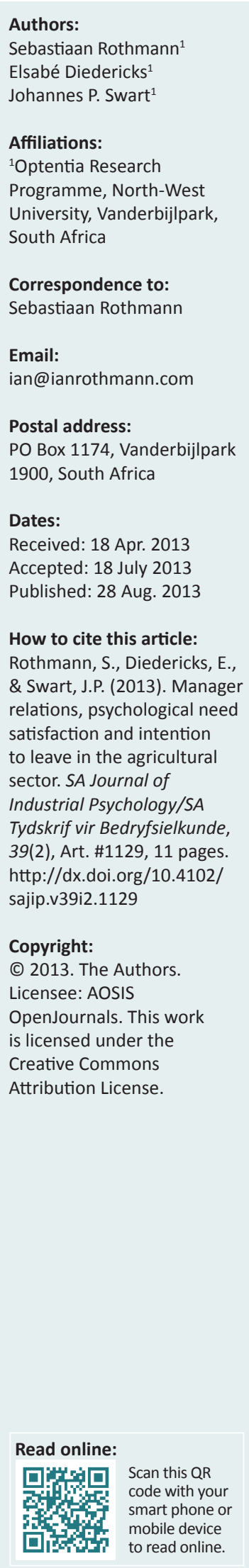

Orientation: If South African organisations are to retain talented and skilled staff, they need to consider the psychological needs of employees and their predictors.

Research purpose: The aim of this study was to investigate the relationship between manager relations, the satisfaction of the psychological needs of employees and their intentions to leave.

Motivation for the study: The effective retention of skilled employees is necessary in organisations in South Africa. However, studies on the psychological processes (and specifically the satisfaction of psychological needs), through which manager relations could promote the retention of staff, are necessary.

Research design, approach and method: The authors used a cross-sectional survey design. They drew convenience samples of managers in agricultural organisations $(N=507)$ in South Africa. They administered the Manager Relations Scale, the Work-related Basic Need Satisfaction Scale and the Turnover Intention Scale.

Main findings: The results confirmed a model in which manager relations affected the satisfaction of psychological needs and intentions to leave. Autonomy satisfaction mediated the relationship between manager relations and the intentions of employees to leave.

Practical/managerial implications: Managers should participate in training on applying selfdetermination theory to support the autonomy and the relatedness satisfaction of employees.

Contribution/value add: This study contributes to the literature by exploring the processes through which manager relations influence the intentions of employees to leave.

\section{Introduction}

\section{Background to the study}

Attracting and retaining skilled employees is a major challenge for organisations because of the global shortage of qualified candidates for skilled positions (Lowry, Turner \& Fisher, 2006) and the high turnover of talented employees. Challenges that currently face human resource managers in South Africa include, amongst others, retaining key talent, lack of employee recognition and management problems (Koketso \& Rust, 2012).

The effective retention of qualified staff requires that organisations create pleasant work environments that are conducive for building effective relationships with employees (Armstrong, 2006). Various studies (Kahn, 1990; May, Gilson \& Harter, 2004; Rothmann \& Rothmann, 2010; Schaufeli \& Bakker, 2004) emphasise the importance of manager relations for the optimal functioning of employees. Kouzes and Posner (2002) summarise the importance and effects of managers on employees:

A key factor in why people stay in organizations is their managers. It's equally important in why people leave organizations. People, in fact, don't generally quit companies, they quit managers. (p. 283)

One can define turnover as the 'individual movement across the membership boundary of an organization' (Price, 2001, p. 600). Employees' intentions to stay or leave organisations are the best predictors of voluntary turnover (Griffeth, Hom \& Gaertner, 2000). According to Harris, Kacmar and Witt (2005), it makes more sense to study turnover intention than actual turnover. Because intention to leave will vary between employees in the same job and organisation, it is important to understand their antecedents. These antecedents include job demands and resources as well as the psychological processes that precede well-being and intention to leave. Knowledge about intention to leave and its antecedents can help organisations correct the conditions that lead to thoughts of leaving (Costigan, Insinga, Berman, Kranas \& Kureshov, 2011). Research on the intentions of employees to leave and their antecedents should benefit organisations.

Deci and Ryan's $(1985,2008$ a) self-determination theory (SDT) is one theoretical framework that could explain why manager relations affect intentions to leave. SDT is part of the eudaimonic 
perspective of well-being and focuses on the content of one's life and the processes involved in living well and engaging the best human capacities towards pursuing virtue and excellence (Ryan, Huta \& Deci, 2008; Waterman, 2008). All employees strive inherently to develop and actualise their potential. According to the SDT, this is subordinate to employees' ability to satisfy their three inborn psychological needs for autonomy, relatedness and competence (Deci \& Ryan, 1985, 2008a). Experiences in the work environment influence the psychological need satisfaction of employees (Baard, Deci \& Ryan, 2004). SDT research has focused on the factors that enable or hinder the satisfaction of these psychological needs. Satisfying these inherent needs lead to motivation and better functioning. The opposite is also trueconditions that prevent need satisfaction impede motivation and optimal functioning (Deci \& Ryan, 2000).

Supportive and trusting manager relations may affect psychological need satisfaction and intentions to leave (Van den Broeck, Vansteenkiste, De Witte \& Lens, 2008). Satisfying psychological needs could result in positive work-related outcomes and low intentions to leave (Baard et al., 2004).

This study will contribute to the literature by exploring the processes through which manager relations affect intentions to leave. The aim of this study was to investigate the relationships between manager relations, satisfying psychological needs and the intentions of employees to leave. It aims to build on the application of SDT by investigating the effects of supportive, trusting and non-controlling managers on satisfying psychological needs and retaining employees.

\section{Self-determination theory: The role of psychological need satisfaction}

Self-determination theory can explain the causality between human behaviour and its results (Deci \& Ryan, 1985; Ryan \& Deci, 2000). More specifically, SDT can explain motivation at work (Deci \& Ryan, 1985). In SDT, motivation ranges from autonomous, which stems from within the self (selfconcordant), to controlled, which comes from outside pressure (Deci \& Ryan, 2008b).

Intrinsic motivation is an example of autonomous motivation. People will engage in an activity voluntarily if they find it interesting (Gagné \& Deci, 2005; Ryan \& Deci, 2002). The intrinsic motivation that occurs when employees undertake an activity out of interest, enjoyment or inherent satisfaction has three parts: intrinsic motivation to know, intrinsic motivation to accomplish and intrinsic motivation to experience stimulation. Satisfying the three psychological needs of autonomy, competence and relatedness stimulate intrinsic motivation (Gagné \& Deci, 2005).

Activities that are not intrinsically motivating require extrinsic motivation. Extrinsic motivation refers to activities people undertake when they are not interested in them (Ryan \& Deci, 2002). SDT proposes that extrinsic motivation can vary in the degree to which it is autonomous or controlled.
According to Ryan and Deci (2002), one can classify extrinsic motivation as integration, identification, introjection and external regulation (Ryan \& Deci, 2002). Integrated regulation occurs when one recognises an activity as worthwhile because one sees it as a means to an end. Identification occurs when employees identify that an activity is worthwhile for a specific reason. Rewards and restrictions that employees introduce themselves govern introjected regulation. Rewards and restrictions that others introduce govern external regulation. The latter type of motivation is the lowest type of motivation on the self-determination continuum (Ryan \& Deci, 2002).

In the workplace, the basic premise of SDT is that satisfying the three universal and innate psychological needs (autonomy, competence and relatedness) is a prerequisite for intrinsic motivation, internalising work behaviour and thriving (Deci \& Ryan, 2008a, 2008b). Work environments that foster these innate needs facilitate well-being (Deci \& Ryan, 2000), because satisfying basic psychological needs provides the nutriments for intrinsic motivation and internalisation (Gagné \& Deci, 2005). Satisfying psychological needs will improve employees' intrinsic motivation, promote internalising extrinsic motivation and lead to organisational commitment, which will contribute to staff retention (Gagné \& Deci, 2005).

In this regard, autonomy-supportive interpersonal environments play the most significant role. The value of SDT in the workplace is evident when managers empower their subordinates by paving the way for them to satisfy their psychological needs.

According to Deci and Ryan (2011), the need for autonomy refers to the desire to experience freedom and choice when carrying out an activity. The need for competence refers to employees' inherent desire to feel effective in interacting with the environment. The need for relatedness refers to the innate need of employees to feel connected to others, to love and care for others as well as for others to love and care for them. When employees experience a sense of communion, and develop close and intimate relationships with others, they satisfy this need. Satisfying all three of these needs is important for optimal functioning and well-being (Deci \& Ryan, 2000).

If a work environment provides adequate support for satisfying the three needs, it should generate more participation from employees because they would associate it with greater autonomous motivation. Milyavskaya and Koestner (2011) have shown that satisfying the basic needs for autonomy, competence and relatedness leads to autonomous motivation. This, in turn, leads to positive employee and organisational outcomes. According to Sheldon and HouserMarko (2001), employees who set themselves autonomous goals achieved more of them. This motivates them to set and achieve goals that are more autonomous in the future and, in so doing, increases their own well-being. The degree to which goals are autonomous will determine employees' energy to achieve their goals. The goals that employees achieve 
relate to their psychological need for satisfying their desire for autonomy, competence and relatedness. These, in turn, are essential for optimal human development and integrity (Gagné \& Deci, 2005) and lead to positive organisational outcomes (Greguras \& Diefendorff, 2010).

Autonomy support relies on managers understanding and acknowledging employees' perceptions, supplying information, providing opportunities and encouraging self-initiation. Baard et al. (2004) state that employees, who perceived their managers as being more supportive of autonomy, exhibited greater job satisfaction and better well-being. Competence and relatedness are necessary for motivation, whether autonomous or controlled, and are implicit in autonomy support (Deci \& Ryan, 2000). A work environment, which autonomy support characterises, will elicit overall need satisfaction (i.e. of all three needs) and result in greater work engagement and psychological wellbeing. Because satisfying all three needs is essential for well-being, collective need satisfaction relates positively to motivation and well-being. Research has shown that autonomous motivation predicts persistence and leads to effective performance, especially on difficult or heuristic tasks that demand creativity and innovative problem-solving (Deci \& Ryan, 2008b).

Three specific factors (that provide a meaningful rationale for doing a task, acknowledge that employees might not find an activity interesting and emphasise choice rather than control) facilitate internalising extrinsic motivation (Deci \& Ryan, 2011). Employees' intrinsic motivation and internalising extrinsic motivation contribute to two components of organisational commitment (identifying with an organisation and internalising its values). Therefore, one can regard satisfying psychological needs as an important mediator between autonomy support from managers and intentions to leave (Demir \& Özdemir, 2010; Van den Broeck et al., 2008).

\section{Manager relations and satisfying psychological needs}

Scholars often use management and supervision interchangeably, implying the same activity. However, closer perusal of the literature indicates that management is more about agreeing on concrete goals that an organisation should achieve within a set period whilst supervision is more concerned with the day-to-day execution of activities to ensure that the organisation meets the set goals.

Modern day supervisors have generally abandoned the authoritarian control of set goals and regard employees as integral to achieving them. Therefore, the emphasis is more on closer relationships with employees and co-workers as well as mutual support (Grobler, Wärnich, Carrell, Elbert \& Hatfield, 2006). Supportive manager relationships strengthen employees' social identities and generate greater meaningfulness in the workplace (May et al., 2004). Consequently, an important determinant of employees' commitment and intentions to leave is manager relations (May et al., 2004; Rothmann \& Rothmann, 2010).

A manager, who is empathic about employees' needs, shows support, is dependable, empowers employees towards expanding their skills, provides positive feedback and inspires open communication channels through which employees can express their concerns and solve work-related problems, can foster a safe work environment that is conducive to employee well-being (Deci \& Ryan, 1985; May et al., 2004). Deci, Connell and Ryan (1989) found that the managers of a Fortune 500 company, who supported autonomy, had employees who experienced more job satisfaction, were more trusting of top managers and felt less pressured and controlled. According to Deci and Ryan (1985), a supportive manager will show concern for the needs and feelings of employees, encourage them to voice their concerns, assist them to develop new skills, help them to solve work-related problems and provide positive feedback to them. This kind of support will encourage employees to be interested in their work and increase their autonomy. Supportive managers will play a crucial role in employees' commitment to their organisations and to remaining with them.

Trust is an integral component in the manager-employee relationship. The following behavioural categories indicate employees' perceptions of an employment relationship in which trustworthiness triumphs: predictability, integrity, sharing and delegating control, accurate and transparent communication and showing concern (May et al., 2004). In a study involving teachers, the researchers found that managers' appreciation and support enable employees to cope with their job demands and reduce their intentions to leave (Bakker, Hakanen, Demerouti \& Xanthopoulou, 2007). A manager directly and indirectly controls all facets that influence turnover tendencies and can prevent the costly implications of employee turnover, whilst retaining their talent and value to organisations (Costigan et al., 2011; Nienaber \& Masibigiri, 2012). Research by Costigan et al. (2011) showed a correlation of -0.36 between supervisor trust and intentions to leave.

Social exchanges at work help to satisfy psychological needs. According to the social exchange theory (Blau, 1964), employees enter social exchanges when they perceive that the other party is able to contribute to the relationship. If both parties benefit from such an exchange over time, both parties gradually increase their contributions to such an extent that there is a justifiable balance between each party's contributions and their worth. Abusive supervision decreases employees' perceptions of the quality of social exchanges in their organisations. This, in turn, results in deviant behaviours that harm their organisations (Thau, Bennett, Mitchell \& Marrs, 2009). Managers who invest in, and acknowledge, the efforts of employees could encourage strong social exchange relationships. When managers behave unpredictably, inconsistently or hypocritically, employees may show a greater inclination to leave (May et al., 2004). Liu, Siu and Shi (2010) found that continued positive relationships between 
manager and employee generated similar trustworthy and supportive relationships in social exchanges. These will positively affect relatedness satisfaction.

\section{Hypotheses}

Based on a review of the literature, the authors argue that relations with managers influence whether organisations satisfy the psychological needs for autonomy, competence and relatedness, which influence the intentions of employees to leave. Organisations have realised that, in order to retain employees, they have to create work environments that regard collegial inter-relatedness and supportive supervision as important antecedents for personal and organisational growth. Supportive relationships satisfy the three psychological needs for autonomy, competence and relatedness individually and collectively, and lead to lower levels of intentions to leave (Chalofsky \& Krishna, 2009; Patrick, Knee, Caravello \& Lonsbary, 2007).

Given the analytical strategy, and based on the literature review, the authors set the following hypotheses for this study:

Hypothesis 1: supportive manager relations relate positively to autonomy satisfaction.

Hypothesis 2: supportive manager relations relate positively to competence satisfaction.

Hypothesis 3: supportive manager relations relate positively to relatedness satisfaction.

Hypothesis 4: supportive manager relations relate negatively to intentions to leave.

Hypothesis 5: supportive manager relations affect intentions to leave negatively and indirectly by satisfying psychological needs.

\section{Research design Research approach}

The authors used a quantitative research approach to achieve their research objectives. More specifically, they used a crosssectional survey design to collect data on the experiences of manager support and trust, psychological need satisfaction and the intentions of employees to leave at a particular point in time.

\section{Research method \\ Research participants}

Eight agricultural companies participated in the study. The number of participants varied from as few as four per company to 199 in the case of the larger companies. The companies included formal secondary agricultural companies (previously called cooperatives), a large fertilizer producer to the agricultural sector and fruit packaging companies. The ages of the participants varied from 23 to 63 (Mean $=42.42$; SD $=9.45$ ). The length of service in the various companies varied between one and 45 years $($ Mean $=19.35 ; \mathrm{SD}=9.93)$. Table 1 gives the characteristics of the participants $(N=507)$.
TABLE 1: Characteristics of the participants $(N=507)$.

\begin{tabular}{|c|c|c|c|}
\hline Item & Author to provide header & $f$ & $\%$ \\
\hline \multirow[t]{2}{*}{ Gender } & Male & 406 & 80.1 \\
\hline & Female & 101 & 19.9 \\
\hline \multirow[t]{5}{*}{ Race } & White & 455 & 89.7 \\
\hline & African & 16 & 3.2 \\
\hline & Coloured ${ }^{\dagger}$ & 29 & 5.7 \\
\hline & Indian & 5 & 1.0 \\
\hline & Other & 2 & 0.4 \\
\hline \multirow[t]{3}{*}{ Home language } & Afrikaans & 470 & 92.7 \\
\hline & English & 21 & 4.1 \\
\hline & African & 16 & 3.2 \\
\hline \multirow[t]{5}{*}{ Education } & Grade 12 & 194 & 38.3 \\
\hline & $\begin{array}{l}\text { Further education and training college } \\
\text { diploma }\end{array}$ & 46 & 9.1 \\
\hline & Technikon diploma & 63 & 12.4 \\
\hline & Bachelor degree & 104 & 20.5 \\
\hline & Postgraduate degree & 100 & 19.7 \\
\hline \multirow[t]{4}{*}{ Job level } & Executive management & 26 & 5.1 \\
\hline & Senior management & 74 & 14.6 \\
\hline & Middle management & 239 & 47.1 \\
\hline & Junior management & 168 & 33.1 \\
\hline
\end{tabular}

$f$, frequency.

$\leftarrow$, Coloured is a South African term to describe people of mixed racial descent.

Males comprised $80.1 \%$ of the sample and females $19.9 \%$. With regard to race, White people dominated the sample (89.7\%), followed by Africans (3.2\%), Coloureds (5.7\%) and Indians (1\%). With regard to education, $61.7 \%$ of the participants had tertiary qualifications. The distribution of participants by management level was: middle management $(47.1 \%)$, junior management $(33.1 \%)$, senior management $(14.6 \%)$ and executive level (5.1\%).

\section{Measuring instruments}

The authors used the Manager Relations Scale (MRS) (May et al., 2004) to measure the participants' experiences of manager support (five items) and trust (five items). Examples of the items are: 'My manager encourages employees to participate in important decisions' and 'My manager does what he or she says he or she will do'. Each item requires respondents to answer on a scale that varies from 1 ('strongly disagree') to 7 ('strongly agree'). Rothmann and Rothmann (2010) found an alpha coefficient of 0.95 for the onedimensional scale.

The authors used the Work-related Basic Need Satisfaction Scale (WBNSS) (Van den Broeck, Vansteenkiste, De Witte, Soenens \& Lens, 2010) to measure the satisfaction of psychological needs. The WBNSS measures the satisfaction of three psychological needs: autonomy (six items, like 'I feel like I can pretty much be myself at work'), competence (six items, like 'I feel competent at work') and relatedness (eight items, like 'People at work care about me'). The authors evaluated the items using a five-point scale that varies from 1 ('totally disagree') to 5 ('totally agree'). Research by Swart (2012) supported the three-factor structure of the WBNSS. Alpha coefficients of $0.81,0.79$ and 0.79 confirm the reliability for autonomy, competence and relatedness satisfaction respectively (Diedericks, 2012).

The authors used the Turnover Intention Scale (TIS) (Sjöberg \& Sverke, 2000) to measure intentions to leave. The TIS 
consists of three items. An example of an item is "If I was completely free to choose I would leave this job". Response options ranged from 1 ('strongly disagree') to 5 ('strongly agree'). The authors found an alpha coefficient of 0.83 for the TIS. Diedericks found an alpha coefficient of 0.79 for the TIS in a study in South Africa.

\section{Research procedure}

The Ethics Committee of the North-West University (Vaal Triangle Campus), South Africa, evaluated and accepted the research project.

The authors explained the research process to the participants. They allowed participants to ask questions and raise concerns about the project before considering participation. The authors outlined the roles and responsibilities of all the parties involved. Participation in the project was anonymous and voluntary. The authors gave the participants a consent form that stated that the authors would use the information they obtained from the study for research purposes only. The participants had the opportunity to receive feedback on the results of the study.

The authors administered a survey questionnaire to the participants electronically. A covering letter accompanied the questionnaire. It explained the purpose and emphasised the confidentiality of the research project. The authors contacted the managers of the agricultural organisations to introduce the research topic to them and to obtain permission to involve their employees in the project. The authors made the questionnaires available online between May 2011 and July 2011. They captured the raw data and converted them to an SPSS dataset.

\section{Statistical analysis}

The authors conducted the initial analyses using the SPSS 21.0 program (SPSS, 2013). They used SPSS to create a data file and to compute descriptive statistics.

The authors analysed the data using Mplus version 7.0 (Muthén \& Muthén, 1998-2012). The authors defined the items of all questionnaires as continuous and used a maximum likelihood (ML) estimator.

The authors used the following Mplus indexes in this study:

1. Absolute fit indices, which included the Chi-square statistic (the test of absolute fit of the model), the Standardized Root Mean Residual (SRMR) and the RootMeans-Square Error of Approximation (RMSEA).

2. Incremental fit indices, which included the Tucker-Lewis Index (TLI).

3. The Comparative Fit Index (CFI). (Hair, Black, Babin \& Andersen, 2010)

The authors regarded TLI and CFI values higher than 0.90 as acceptable. Root-Means-Square Error of Approximation values lower than 0.08 and a SRMR lower than 0.08 indicate a close fit between the model and the data.

\section{Results}

Firstly, the authors report the results of tests of competing measurement models. Secondly, they report the results of tests of alternative structural models.

\section{Testing the measurement model}

Using confirmatory factor analysis (CFA), the authors tested a five-factor measurement model as well as alternative models to assess whether each of the measurement items would load significantly onto the scales with which they were associated. The authors tested five measurement models.

Model 1 consisted of five latent variables:

1. Manager relations, which consisted of two latent variables: manager support (measured by five observed variables) and manager trust (measured by five observed variables).

2. Autonomy satisfaction (measured by six observed variables).

3. Competence satisfaction (measured by six observed variables).

4. Relatedness satisfaction (measured by eight observed variables).

5. Intention to leave (measured by three observed variables).

The authors allowed all the latent variables in model 1 to correlate.

Models 2, 3, 4 and 5 followed the same template. The authors specified 10 observed variables for model 2 to measure manager relations (without the two first-order latent variables of manager support and trust). They specified 20 observed variables for model 3 to measure psychological need satisfaction (without the three first-order latent variables of autonomy, competence and relatedness satisfaction). They specified all observed variables for model 4 that loaded onto one latent variable. For model 5, they specified the secondorder latent variables of manager relations (which consisted of two first-order latent variables: manager support and trust) and psychological need satisfaction (which consisted of three first-order latent variables: autonomy, competence and relatedness satisfaction).

Table 2 presents fit statistics for the test of the various models.

The authors obtained a $\chi^{2}$ value of $1346.02(d f=483)$ for the hypothesised measurement model. The fit statistics on the four fit indices were acceptable: TLI $=0.90, \mathrm{CFI}=0.91$, RMSEA $=0.06$ and SRMR $=0.05$. The hypothesized model had an acceptable fit with the data on four of the fit indices.

The authors used two fit statistics, the Akaike Information Criterion (AIC) and Bayes Information Criterion (BIC) in addition to other fit indices in this study, to compare alternative measurement models. The AIC, which is a comparative measure of fit, is meaningful when one estimates different models. The lowest AIC is the best fitting model. 
The BIC provides an indication of model parsimony (Kline, 2010). Comparison of the fit indices indicates that model 1 fitted the data best.

Analyses continued in an exploratory mode to improve the fit of the selected model. The modification index $(\mathrm{MI}=43.26)$ for item 1 ('My manager helps me solve work-related problems') and item 2 ('My manager encourages me to develop new skills') of the MRS showed that one could improve the model fit by correlating the errors of the items. Correlated errors could represent respondent characteristics that reflect bias, social desirability as well as a high degree of overlap in item content (Byrne, 2010). The fit statistics for the revised model (model 6) showed that the model fit improved significantly when the authors allowed the errors of the items to correlate.

The authors obtained a $\chi^{2}$ value of $1302.72(d f=482)$ for the hypothesised measurement model. The fit statistics on the four fit indices were acceptable: TLI $=0.90, \mathrm{CFI}=0.91$, RMSEA $=0.05, \mathrm{SRMR}=0.05, \mathrm{AIC}=38396.59$ and $\mathrm{BIC}=38870.19$.

Furthermore, the authors removed one item that measured intention to leave ('If I have my own way, I will be working for this organisation one year from now') because of its high residual variance. They respecified the model without this item. This resulted in an improved fit $\left(\chi^{2}=1302.72\right.$; $d f=48 ; \mathrm{TLI}=0.91 ; \mathrm{CFI}=0.91, \mathrm{RMSEA}=0.05$ and SRMR $=$ 0.05$, AIC $=36861.43$ and $\mathrm{BIC}=37322.34)$. Standardised coefficients from items to factors ranged from 0.60 to 0.90 . Furthermore, the results showed that the relationship between each observed variable and its respective construct was statistically significant $(p<0.01)$. This established the posited relationships between indicators and constructs (see Hair et al., 2010).

\section{Testing the structural model}

Table 3 reports the descriptive statistics, reliabilities and correlations of the MRS, WBNSS and TIS. It shows scale reliabilities that range from 0.82 to 0.95 . This shows acceptable internal consistency (Nunnally \& Bernstein, 1994).
The authors tested the structural model based on the measurement model. They tested the hypothesised relationships using latent variable modelling as Mplus implements it (Muthén \& Muthén, 1998-2012). They tested three competing measurement models. In Model 7a, they included paths from manager relations to autonomy, competence and relatedness satisfaction; from manager relations to intentions to leave; and from autonomy, competence and relatedness satisfaction to intentions to leave. The results showed a good fit of the hypothesised model to the data: $\chi^{2}(451, N=507)=1245.87 ; p<0.001$; $\mathrm{CFI}=0.91$; TLI $=0.91$; RMSEA $=0.05(90 \%$ CI $0.05-0.06)$, $\mathrm{SRMR}=0.05 ; \mathrm{AIC}=36861.43$ and $\mathrm{BIC}=37322.34$.

Figure 1 and Table 4 show the standardised path coefficients that Mplus estimated for the hypothesised model. The figure shows only statistically significant paths. The authors allowed correlations between autonomy, competence and relatedness satisfaction.

Given the cross-sectional nature of the data, the authors also tested two other competing models. Model $7 \mathrm{~b}$ included paths from manager relations to intentions to leave and from psychological need satisfaction (autonomy, competence and relatedness) to intentions to leave. However, the authors restricted the path from manager relations to psychological need satisfaction to zero. Model $7 \mathrm{c}$ included paths from manager relations to psychological need satisfaction (autonomy, competence and relatedness) and intentions to leave. The authors restricted the paths of autonomy, competence and relatedness satisfaction to intentions to leave to zero.

Model $7 \mathrm{~b}$ yielded the following fit statistics: $\chi^{2}(454, N=507)$ $=1455.52 ; p<0.001 ; \mathrm{CFI}=0.89 ; \mathrm{TLI}=0.88 ; \mathrm{RMSEA}=0.07$ (90\% CI 0.06-0.07); SRMR $=0.15 ;$ AIC $=37065.09$ and BIC $=$ 37513.31. Model 7c showed the following fit statistics: $\chi^{2}(454, N=507)=1333.61 ; p<0.001 ;$ CFI $=0.90 ;$ TLI $=0.90$, RMSEA $=0.06(90 \%$ CI $0.06-0.07) ;$ SRMR $=0.07$; $\mathrm{AIC}=36943.17$ and $\mathrm{BIC}=37391.40$.

TABLE 2: Fit statistics of competing measurement models.

\begin{tabular}{|c|c|c|c|c|c|c|c|c|}
\hline Model & $\chi^{2}$ & $d f$ & TLI & CFI & RMSEA & SRMR & AIC & BIC \\
\hline 1 & 1346.02 & 483 & 0.90 & 0.91 & 0.06 & 0.05 & 38437.89 & 38907.26 \\
\hline 2 & 1510.68 & 485 & 0.88 & 0.89 & 0.07 & 0.05 & 38598.55 & 39059.46 \\
\hline 3 & 2235.26 & 490 & 0.80 & 0.81 & 0.08 & 0.09 & 39313.13 & 39752.90 \\
\hline 4 & 4315.39 & 495 & 0.56 & 0.59 & 0.12 & 0.14 & 41383.27 & 41801.89 \\
\hline 5 & 1406.38 & 487 & 0.89 & 0.90 & 0.07 & 0.06 & 38490.25 & 38942.71 \\
\hline 6 & 1302.72 & 482 & 0.90 & 0.91 & 0.05 & 0.05 & 38396.59 & 38870.19 \\
\hline 7 & 1245.87 & 451 & 0.91 & 0.91 & 0.05 & 0.05 & 36861.43 & 37322.34 \\
\hline
\end{tabular}

$\chi^{2}$, chi-square statistic; $d f$, degrees of freedom; TLI, Tucker-Lewis Index; CFI, Comparative Fit Index; RMSEA, root mean square error of approximation; SRMR, standardised root mean square residual; AIC, Akaike Information Criterion; BIC, Bayes Information Criterion.

TABLE 3: Descriptive statistics, alpha coefficients and correlations of the scales ( $N=507)$

\begin{tabular}{lllllll}
\hline Variable & Mean & SD & $\alpha$ & $\mathbf{1}$ & $\mathbf{2}$ & $\mathbf{3}$ \\
\hline 1. Manager relations & 4.01 & 1.26 & 0.95 & - & - & - \\
2. Autonomy & 3.64 & 0.58 & 0.78 & $0.49^{*}$ & - & - \\
3. Competence & 4.06 & 0.51 & 0.82 & 0.07 & $0.44^{*}$ & - \\
4. Relatedness & 3.77 & 0.59 & 0.86 & $0.48^{*}$ & $0.63^{*}$ & - \\
5. Turnover intention & 2.51 & 0.61 & 0.82 & $-0.29^{*}$ & $-0.34^{*}$ & $-0.15^{*}$ \\
\hline
\end{tabular}

SD, standard deviation; $\alpha$, alpha.

$*, p<0.01$ 
The authors found the following changes in chi-square $\left(\Delta \chi^{2}\right)$ : Models 7a and $7 \mathrm{~b}\left(\Delta \chi^{2}=209.65 ; \Delta d f=3 ; p<0.01\right)$, and models $7 \mathrm{a}$ and $7 \mathrm{c}\left(\Delta \chi^{2}=87.74 ; \Delta d f=3 ; p<0.01\right)$. The AIC and BIC values of model $7 \mathrm{a}$ were also substantially lower than the values for models $7 \mathrm{~b}$ and $7 \mathrm{c}$.

The authors now discuss the relationships of the best fitting and most parsimonious structural model (model 7a) they obtained with reference to the hypotheses of this study.

Hypothesis 1: For the portion of the model that predicts autonomy satisfaction, Table 4 shows that the path coefficient of manager relations $(\beta=0.58 ; p<0.01)$ was statistically significant and had the expected sign. Supportive and trusting manager relations had a positive relationship with autonomy satisfaction. The ML-estimated equation accounted for a large proportion of the variance in autonomy satisfaction $\left(R^{2}=0.34\right)$.

TABLE 4: Standardised regression coefficients of the variables.

\begin{tabular}{lllll}
\hline Variable & Estimate & SE & Est/SE & $p$ \\
\hline $\begin{array}{l}\text { Autonomy satisfaction } \\
\text { Manager relations }\end{array}$ & 0.58 & 0.04 & 15.26 & $0.001^{* *}$ \\
$\begin{array}{l}\text { Competence satisfaction } \\
\text { Manager relations }\end{array}$ & 0.07 & 0.05 & 1.41 & 0.159 \\
$\begin{array}{l}\text { Relatedness satisfaction } \\
\text { Manager relations }\end{array}$ & 0.55 & 0.04 & 14.89 & $0.001^{* *}$ \\
$\begin{array}{l}\text { Turnover intention } \\
\text { Manager relations }\end{array}$ & -0.15 & 0.07 & -2.22 & $0.026^{*}$ \\
$\begin{array}{l}\text { Autonomy satisfaction } \\
\text { Competence satisfaction }\end{array}$ & -0.39 & 0.10 & -3.86 & $0.001^{* *}$ \\
Relatedness satisfaction & -0.04 & 0.07 & -0.58 & 0.559 \\
\hline
\end{tabular}

$\mathrm{SE}$, standard error; $\mathrm{Est} / \mathrm{SE}$, estimate divided by standard error; $p$, obtained significance value. ${ }^{*}, p<0.05 ; * *, p<0.01$
The authors accept Hypothesis 1.

Hypothesis 2: For the portion of the model that predicts competence satisfaction, the path coefficient of manager relations was not statistically significant $(\beta=0.07 ; p>0.05)$.

The authors reject Hypothesis 2.

Hypothesis 3: For the portion of the model that predicts relatedness satisfaction, Table 4 shows that the path coefficient of manager relations $(\beta=0.55 ; p<0.01)$ was statistically significant and had the expected sign. Supportive and trusting manager relations had a positive relationship with relatedness satisfaction. The ML-estimated equation accounted for a large proportion of the variance in autonomy satisfaction $\left(R^{2}=0.30\right)$.

The authors accept Hypothesis 3.

Hypothesis 4 and Hypothesis 5: For the portion of the model that predicts intentions to leave, the path coefficients of manager relations $(\beta=-0.15 ; p<0.05)$, autonomy satisfaction $(\beta=-0.40 ; p<0.01)$ and relatedness satisfaction $(\beta=-0.16 ; p<$ $0.05)$ were statistically significant and had the expected signs.

The authors partially accept Hypothesis 4 .

To determine whether psychological need satisfaction indirectly affected any relationships in the model, the authors used the procedure that Hayes (2009) explained. They used bootstrapping to construct two-sided bias-corrected 95\% confidence intervals (CIs) to evaluate indirect effects.

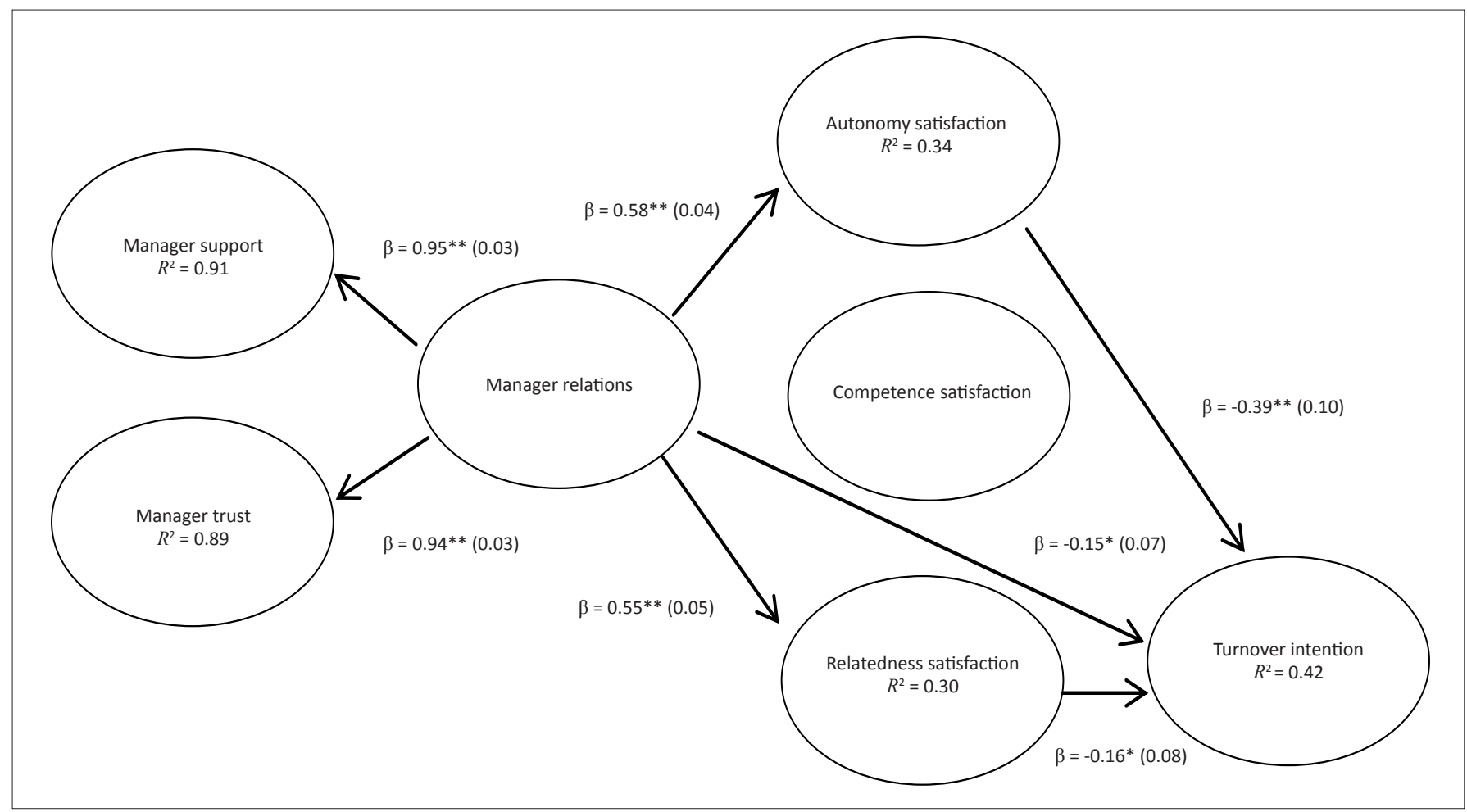

FIGURE 1: The structural model - standardised solution with standard errors in parentheses $\left({ }^{*}, p<0.05 ;{ }^{* *}, p<0.001\right)$. 
TABLE 5: Indirect effects of manager relations on turnover intention via psychological need satisfaction.

\begin{tabular}{llll}
\hline Variable & Estimate & SE & $\mathbf{9 5 \% ~ B C ~ C l}$ \\
\hline Sum of indirect effects & -0.32 & 0.06 & {$[-0.44,-0.20]$} \\
Autonomy satisfaction & -0.23 & 0.09 & {$[-0.40,-0.06]$} \\
Competence satisfaction & -0.00 & 0.01 & {$[-0.02,0.01]$} \\
Relatedness satisfaction & -0.09 & 0.06 & {$[-0.21,0.03]$} \\
\hline
\end{tabular}

$\mathrm{SE}$, standard error; $\mathrm{BC} \mathrm{Cl}$, bias-corrected confidence interval.

Table 5 reports lower and upper CIs.

With regard to the indirect effects of manager relations on intentions to leave, the $95 \%$ CIs of autonomy satisfaction did not include zero. Therefore, manager support and trust had indirect effects on intentions to leave by satisfying the need for autonomy. The authors partially accept Hypothesis 5 with regard to the indirect effects of manager relations on intentions to leave (through autonomy satisfaction).

Taken together, the model fit indices suggest that the relationships posited in the model account for a substantial amount of the covariation in the data. The model accounts for $34 \%$ of the variance in autonomy satisfaction, 30\% of the variance in relatedness satisfaction and $42 \%$ of the variance in intentions to leave. This gives further empirical support for the fit of the model.

\section{Discussion}

The aim of this study was to investigate the relationships between manager relations, psychological need satisfaction and the intentions of employees to leave. Supportive and trusting relations with managers had direct effects on two dimensions of psychological need satisfaction: autonomy and relatedness. Manager relations explained relatively large percentages of the variance in autonomy and relatedness satisfaction, but did not affect competence satisfaction significantly. Poor relationships with managers affected intentions to leave directly, although the effect size was small. However, the results showed that poor relationships with managers indirectly affected the intentions of employees to leave because of a lack of autonomy satisfaction.

The results confirmed that supportive and trusting manager relations have negative relationships with intentions to leave. Previous research supported this finding. In fact, researchers have argued that employees leave managers rather than organisations (Kouzes \& Posner, 2002). Supportive and trusting manager relationships strengthen employees' social identities and generate greater meaningfulness in the workplace. This results in greater employee commitment to organisations and lower intentions to leave (May et al., 2004; Rothmann \& Rothmann, 2010). Bakker et al. (2007) showed that managers' support could enable employees to cope better with job demands, thus reducing their intentions to leave.

Supportive and trusting manager relationships predicted the intentions of employees to leave in this study even when the authors controlled for psychological need satisfaction.
However, the effect size was small. Furthermore, supportive and trusting manager relationships had strong effects on autonomy satisfaction (they explained $34 \%$ of the variance) and relatedness satisfaction (they explained $30 \%$ of the variance). Managers who are supportive and trusting contribute to the autonomy and the relatedness satisfaction of employees. Supportive managers are those who help employees to solve work-related problems, encourage them to develop new skills, stay informed about what employees think and feel and praise good work. Managers who are trusting encourage employees to speak up when they disagree with decisions, treat them fairly, are committed to protecting their interests and doing what they say they would.

Autonomy satisfaction implies that employees perceive that they direct and determine their own behaviour, whilst relatedness satisfaction implies that employees experience a sense of communion and develop close and intimate relationships with others (Deci \& Ryan, 2011). Therefore, supportive and trusting manager relations play important roles in satisfying psychological needs (i.e. autonomy and relatedness satisfaction) in the work context (Deci \& Ryan, 2000).

Supportive and trusting relationships with managers did not contribute significantly to competence satisfaction in this study. The need for competence refers to employees' inherent desire to feel effective in interacting with the environment and results from mastering a task. Competence satisfaction allows employees to adapt to complex and changing environments (Deci \& Ryan, 2011).

Contrary to the authors' Hypothesis, supportive and trusting relationships with managers did not play a significant role in the competence satisfaction of employees in this study. One could offer various reasons for this finding.

Firstly, although competence satisfaction is necessary for motivation, it is implicit in autonomy support (Deci \& Ryan, 2000). Therefore, a work environment that supports autonomy satisfaction, will elicit overall need satisfaction (i.e. of all three needs). The results of this study confirm that autonomy and competence satisfaction are indeed related.

Secondly, managers might not be sufficiently skilled and motivated to demonstrate behaviour (like mastery, vicarious experiences and verbal persuasion) to elicit the competence satisfaction of employees (Bandura, 1997, 2000).

Another explanation for the small effect of supportive and trusting manager relations on competence satisfaction is that the scale that measured manager relations might not measure competence-promoting behaviour adequately. Being supportive and trusting might help to satisfy the psychological needs for autonomy and relatedness. However, such behaviour of managers might not be enough to satisfy the psychological need for competence. Delegating authority, emphasising accountability, encouraging self-directed 
decision-making, developing skills and coaching to promote innovation (Konczak, Stelly, \& Trusty, 2000) will promote the autonomy satisfaction of employees and will contribute to competence satisfaction. Mendes and Stander (2011) found that promoting role clarity (by reducing role ambiguity and conflict) could promote experiences of competence, which affect the retention of employees.

Poor manager relations and low satisfaction of the psychological needs for autonomy and relatedness had a strong effect on the intentions of employees to leave (they explained $42 \%$ of the variance). However, this study showed that the nature of the effects differed for autonomy and relatedness satisfaction. Poor manager relations affected employees' intentions to leave indirectly because of low autonomy satisfaction. Relatedness satisfaction had a direct effect on employees' intentions to leave. However, this study did not support an indirect effect of poor manager relations on intention to leave because of low relatedness satisfaction.

Poor manager relations (evident in low support and low trust characterises) indirectly affected the intention to leave because of unfulfilled needs for autonomy. Consistent with the findings of Gagné and Deci (2005), it seems that autonomy-supportive interpersonal environments play a significant role in retaining staff, increasing employees' intrinsic motivation and promoting the internalisation of extrinsic motivation. Autonomy satisfaction mediated the relationship between manager relations and intentions to leave. If employees feel that managers are not supportive and cannot be trusted, they will experience less autonomy satisfaction. This, in turn, leads to the intention to leave.

Autonomy satisfaction, which refers to satisfying the desire to experience freedom and choice when carrying out an activity (Deci \& Ryan, 2011), is therefore an important psychological condition that changes the effect of perceived manager support to an intention to leave organisations (Deci \& Ryan, 2008a). Supportive and trusting relationships with managers seem important to satisfying psychological needs. If managers support autonomous goal setting and achievement by being supportive and creating an atmosphere of trust, satisfying psychological needs (specifically autonomy and relatedness satisfaction) result. This is essential for optimal human development (Gagné \& Deci, 2005), and positive organisational outcomes (Greguras \& Diefendorff, 2010).

\section{Managerial implications and recommendations}

Organisations should conduct surveys to assess manager support and trust, psychological need satisfaction and intentions to leave. It is also necessary to investigate manager relations, psychological satisfaction and intentions to leave in different ways and at different times.

The authors recommend that organisations address the following aspects to support retention in organisations in the agricultural sector.
Firstly, organisations should introduce interventions to create supportive climates that are conducive to quality and trusting manager-subordinate relations and clear communication channels that would reduce intentions to leave. Secondly, organisations should create environments that support the satisfaction of psychological needs. They can achieve this by considering the perspectives of employees, encouraging initiative and a sense of choice, being responsive to the ideas, questions and initiatives of employees as well as promoting learning, competence and belonging (Deci \& Ryan, 2008a, 2008b). Providing a meaningful rationale for completing tasks, acknowledging that employees might not find activities interesting and emphasising choice rather than control will contribute to autonomy satisfaction, intrinsic motivation and internalising extrinsic motivation (Deci \& Ryan, 2011).

\section{Suggestions for future research}

Future research could examine the antecedents of psychological need satisfaction (specifically competence) at work using a longitudinal design. Longitudinal studies could provide more insight into the effects of manager relations on satisfying psychological needs and the intentions of staff to leave. Future studies should include larger samples and be more representative in terms of gender and cultural diversity. Researchers should adapt the scale that measured manager relations in this study to include more competencepromoting behaviours of managers.

\section{Limitations of the study}

The study had several limitations. Firstly, the sample was relatively homogeneous in gender and culture. Secondly, the researchers could not prove the causality of relationships because the findings of the study used correlational data. Thirdly, the two-item turnover intention scale needs revision.

\section{Conclusion}

The results of this study confirm the importance and usefulness of self-determination theory for understanding the association between supportive and trusting manager relations and the intentions of employees to leave. Supportive and trusting relationships that managers initiate helped to reduce the intentions of employees to leave by satisfying employees' autonomy needs.

Supportive and trusting relationships between managers and employees in the agricultural sector satisfy employees' needs to experience freedom of choice when they perform activities. This, in turn, affects their intention to leave their organisations. Furthermore, supportive and trusting relationships with managers contribute to the relatedness satisfaction of employees, which experiences of a sense of communion characterise and to developing close and intimate relationships with others.

\section{Acknowledgements}

This work uses the research that the National Research Foundation (NRF) supported as its basis. Any opinion, 
finding, conclusion or recommendation in this article is that of the authors. The NRF does not accept any liability in this regard.

\section{Competing interests}

The authors declare that they have no financial or personal relationship(s) that may have inappropriately influenced them when they wrote this article.

\section{Authors' contributions}

S.R. (North-West University) prepared the article and conducted the statistical analyses. E.D. (North-West University) assisted with writing the article. J.P.S. (North-West University) gathered the data and helped to write the article.

\section{References}

Armstrong, M. (2006). A handbook of human resource management practice (10th edn.). London, United Kingdom: Kogan Page.

Baard, P.P., Deci, E.L., \& Ryan, R.M. (2004). Intrinsic need satisfaction: A motivational basis of performance and well-being in two work settings. Journal of Applied Social Psychology, 34, 2045-2068. http://dx.doi.org/10.1111/j.1559-1816.2004. tb02690.x

Bakker, A.B., Hakanen, J.J., Demerouti, E., \& Xanthopoulou, D. (2007). Job resources boost work engagement, particularly when job demands are high. Journal of Educational Psychology, 99, 274-284. http://dx.doi.org/10.1037/0022 0663.99.2.274

Bandura, A. (1997). Self-efficacy: The exercise of control. New York, NY: Freeman.

Bandura, A. (2000). Cultivate self-efficacy for personal and organizational effectiveness. In E.A. Locke (Ed.), Handbook of principles of organization behaviour (pp. 120136). Oxford, United Kingdom: Blackwell.

Blau, P. (1964). Exchange and power in social life. New York, NY: Wiley.

Byrne, B.M. (2012). Structural equation modelling with Mplus: Basic concepts, applications, and programming. New York, NY: Routledge.

Chalofsky, N., \& Krishna, V. (2009). Meaningfulness, commitment, and engagement The intersection of a deeper level of intrinsic motivation. Advances in Developing Human Resources, 11, 189-203. http://dx.doi.org/10.1177/1523422309333147

Costigan, R.D., Insinga, R.C., Berman, J. J., Kranas, G., \& Kureshov, V.A. (2011). Revisiting the relationship of supervisor trust and CEO trust to turnover intentions: A threecountry comparative study. Journal of World Business, 46, 74-83. http://dx.doi. org/10.1016/j.jwb.2010.05.019

Deci, E.L., Connell, J. P., \& Ryan, R.M. (1989). Self-determination in a work organization. Journal of Applied Psychology, 74, 580-590. http://dx.doi.org/10.1037/00219010.74 .4 .580

Deci, E.L., \& Ryan, R.M. (1985). Intrinsic motivation and self-determination in human behavior. New York, NY: Plenum. http://dx.doi.org/10.1007/978-1-4899-2271-7

Deci, E.L., \& Ryan, R.M. (2000). The "what" and "why" of goal pursuits: Human needs and the self-determination of behavior. Psychological Inquiry, 11, 319-338. http:// dx.doi.org/10.1207/S15327965PLI1104_01

Deci, E.L., \& Ryan, R.M. (2008a). Self-determination theory: A macrotheory of human motivation, development, and health. Canadian Psychology, 49(3), 182-185. http://dx.doi.org/10.1037/a0012801

Deci, E.L., \& Ryan, R.M. (2008b). Facilitating optimal motivation and psychological well-being across life's domains. Canadian Psychology, 49, 14-23. http://dx.doi. org/10.1037/0708-5591.49.1.14

Deci, E. L., \& Ryan, R.M. (2011). Levels of analysis: Regnant causes of behavior and well-being: The role of psychological needs. Psychological Inquiry, 22, 17-22. $\mathrm{http}: / / \mathrm{dx}$.doi.org/10.1080/1047840X.2011.545978

Demir, M., \& Özdemir, M. (2010). Friendship, need satisfaction and happiness. Journa of Happiness Studies, 11, 243-259. http://dx.doi.org/10.1007/s10902-009-9138-5

Diedericks, E. (2012). Flourishing of employees in the information technology industry in South Africa. Unpublished doctoral thesis, North-West University, Vanderbijlpark, South Africa.

Gagné, M., \& Deci, E.L. (2005). Self-determination theory and work motivation Journal of Organizational Behavior, 26, 331-362. http://dx.doi.org/10.1002/ job.322

Greguras, G.J., \& Diefendorff, J.M. (2010). Why does proactive personality predict employee life satisfaction and work behaviors? A field investigation of the mediating role of the self-concordance model. Personnel Psychology, 63, 539560. http://dx.doi.org/10.1111/j.1744-6570.2010.01180.x

Griffeth, R.W., Hom, P.W., \& Gaertner, S. (2000). A meta-analysis of antecedents and correlates of employee turnover: Update, moderator tests and research implications for the next millennium. Journal of Management, 26, 463-488. http://dx.doi.org/10.1177/014920630002600305
Grobler, P.A., Wärnich, S., Carrell, M.R., Elbert, N.F., \& Hatfield, R.D. (2003). Human resource management in South Africa. London, United Kingdom: Thomson Education. PMCid:PMC149762

Hair, J. F., Black, W.C., Babin, B.J., \& Andersen, R.E. (2010). Multivariate data analysis: A global perspective. Upper Saddle River, NJ: Pearson. http://dx.doi.org/10.1016/j. jmva.2009.12.014

Harris, K.J., Kacmar, K.M., \& Witt, L.A. (2005). An examination of the curvilinear relationship between leader-member exchange and turnover. Journal of Organizational behaviour, 26, 363-378. http://dx.doi.org/10.1002/job.314

Hayes, A.F. (2009). Beyond Baron and Kenny: Statistical mediation analysis in the new millennium, Communication Monographs, 76, 408-420. http://dx.doi. org/10.1080/03637750903310360

Kahn, W.A. (1990). Psychological conditions of personal engagement and disengagement at work. Academy of Management Journal, 33, 692-724. http:// dx.doi.org/10.2307/256287

Kline, R.B. (2010). Principles and practice of structural equation modeling. New York, NY: Guilford Press.

Koketso, L. P-J., \& Rust, A. A.B. (2012). Perceived challenges to talent management in the South African public service: An exploratory study of the City of Cape Town municipality. African Journal of Business Management, 6, 2221-2233.

Konczak, L.J., Stelly, D.J., \& Trusty, M.L. (2000). Defining and measuring empowerment leader behaviours: development of an upward feedback instrument Educational and Psychological Measurement, 60, 301-313. http://dx.doi. org/10.1177/00131640021970420

Kouzes, J.M., \& Posner, B.Z. (2002). Leadership challenge. San Francisco, CA: JosseyBass.

Liu, J., Siu, O., \& Shi, K. (2010). Transformational leadership and employee well-being: The mediating role of trust in the leader and self-efficacy. Applied Psychology: An International Review, 59, 454-479. http://dx.doi.org/10.1111/j.14640597.2009.00407.x

Lowry, G., Turner, R., \& Fisher, J. (2006). The contribution of employment satisfaction factors to recruiting, retaining and career development of information systems and technology professionals. The Review of Business Information Systems, 10, 137-150.

May, D.R., Gilson, R.L., \& Harter, L.M. (2004). The psychological conditions of meaningfulness, safety and availability and the engagement of the human spirit at work. Journal of Occupational and Organizational Psychology, 77, 11-37. http:// dx.doi.org/10.1348/096317904322915892

Mendes, F., \& Stander, M.W. (2011). Positive organisation: The role of leader behaviour in employee engagement and turnover intention. SA Journal of Industrial Psychology, 37(1), 1-13. http://dx.doi.org/10.4102/sajip.v37i1.900

Milyavskaya, M., \& Koestner, R. (2011). Psychological needs, motivation, and well-being: A test of self-determination theory across multiple domains. Personality and Individual Differences, 50, 387-391. http://dx.doi.org/10.1016/j. Personality and In
paid.2010.10.029

Muthén L.K., \& Muthén, B.O. (1998-2012). Mplus users' guide (6th edn.). Los Angeles, CA: Muthén \& Muthén.

Nienaber, H., \& Masibigiri, V. (2012). Exploring factors influencing voluntary turnover intent of generation X public servants: A South African case. Acta Commercii, 12(1), 67-84

Nunnally, J.C., \& Bernstein, I.H. (1994). Psychometric theory (3rd edn.). New York, NY McGraw-Hill.

Patrick, H., Knee, C.R., Canevello, A., \& Lonsbary, C. (2007). The role of need fulfilment in relationship functioning and well-being: A self-determination theory and perspective. Journal of Personality and Social Psychology, 92, 434-457. http:// dx.doi.org/10.1037/0022-3514.92.3.434, PMid:17352602

Price, J. (2001). Reflections on the determinants of voluntary turnover International Journal of Manpower, 22, 600-624. http://dx.doi.org/10.1108/ EUM0000000006233

Rothmann, S., \& Rothmann, S. Jr. (2010). Factors associated with employee engagement in South Africa. SA Journal of Industrial Psychology, 36(2), 1-12. http://dx.doi.org/10.4102/sajip.v36i2.925

Ryan, R.M., \& Deci, E.L. (2002). Overview of self-determination theory: An organismicdialectical perspective. In E.L. Deci \& R.M. Ryan (Eds.), Handbook of selfdialectical perspective. In E.L. Deci \& R.M. Ryan (Eds.), Handbook of self-
determination research (pp. 3-33). Rochester, NY: The University of Rochester determination research
Press. PMCid:PMC77420

Ryan, R.M., Huta, V., \& Deci, E.L. (2008). Living well: A self-determination theory perspective on eudaimonia. Journal of Happiness Studies, 9, 139-170. http:// perspective on eudaimonia. Journal of
dx.doi.org/10.1007/s10902-006-9023-4

Schaufeli, W.B., \& Bakker, A.B. (2004). Job demands, job resources, and their relationship with burnout and engagement: A multi-sample study. Journal of Organizational Behavior, 25, 293-315. http://dx.doi.org/10.1002/job.248

Sheldon, K.M., \& Houser-Marko, L. (2001). Self-concordance goal attainment, and the pursuit of happiness: Can there be an upward spiral? Journal of Personality and Social Psychology, 80, 152-165. http://dx.doi.org/10.1037/0022-3514.80.1.152, PMid:11195887

Sjöberg, A., \& Sverke, M. (2000). The interactive effect of job involvement and organizational commitment revisited: A note on the mediating role of turnove intention. Scandinavian Journal of Psychology, 41, 247-252. http://dx.doi. org/10.1111/1467-9450.00194, PMid:11041307

SPSS Inc. (2013). SPSS 21.0 for Windows. Chicago, IL: SPSS Inc.

Swart, J.P. (2012). Antecedents and outcomes of happiness of managers in the agricultural sector in South Africa. Unpublished doctoral thesis, North-West University, Vanderbijlpark, South Africa. 
Thau, S., Bennett, R.J., Mitchell, M.S., \& Marrs, M.B. (2009). How management style moderates the relationship between abusive supervision and workplace deviance: .

Van den Broeck, A., Vansteenkiste, M., De Witte, H., \& Lens, W. (2008). Explaining the relationships between job characteristics, burnout engagement: The role of basic psychological need satisfaction. Work \& Stress, 22, 277-294. http://dx.doi. org/10.1080/02678370802393672
Van den Broeck, A., Vansteenkiste, M., De Witte, H., Soenens, B., \& Lens, W. (2010). Capturing autonomy, relatedness and competence at work: Construction Work-related Basic Need Satisfaction Scale. Journal of Occupational and Organizational Psychology, 83, 981-1002. http://dx.doi. org/10.1348/096317909X481382

Waterman, A.S. (2008). Reconsidering happiness: A eudaimonist's perspective. Journal of Positive Psychology, 3, 234-252. http://dx.doi. org/10.1080/17439760802303002 